\title{
SURFACE ANALYSES AND MODELLING OF
RATE MULTIPLICITY AND INSTABILITIES
}

\author{
Michael P. Harold, Principal Investigator
}

W. Curtis Conner, Co-Investigator

\author{
Department of Chemical Engineering \\ University of Massachusetts \\ Amherst, MA 01003 \\ 413.545.6143
}

\begin{abstract}
Annual Technical Report for third year of three-year grant Period: $1 / 1 / 90 \cdot 12 / 31 / 90$

Submitted to the U.S. Department of Energy

Office of Basic Energy Sciences, Chemical Sciences Division

(Catalysis and Surface Chemistry)

(Current support contract no. 13772)
\end{abstract}

November, 1990
Principal Investigator: Michael P. Harold, Associate Professor of Chemical Engineering
Co-Investigator: W. Curtis Conner, Associate Professor of Chemical Engineering

\section{DISCLAIMER}

\footnotetext{
This report was prepared as an account of work sponsored by an agency of the United States Government. Neither the United States Gnvernment nor any agency thereof, nor any of their employees, makes any warranty, express or implied, or assumes any legal liability or responsibility for the accuracy, completeness, or usefulness of any information, apparatus, product, or process disclosed, or represents that its use would not infringe privately owned rights. Reference herein to any specific commercial product, process, or service by trade name, trademark, manufacturer, or otherwise does not necessarily constitute or imply its endorsement, recommendation, or favoring by the United States Government or any agency thereof. The views and opinions of authors expressed herein do not necessarily state or reflect those of the United States Government or any agency thereof.
} 


\section{Overview}

Catalytic partial and complete oxidations of chemical species are a quite important class of reactions in the production of many commercial chemicals and in the elimination of environmental pollutants. This research focuses on a sub-class of oxidation reactions in which $\mathrm{CO}$ is a key player - be it a reactant, intermediate, or product - in the catalytic sequence and chemistry. Our interest in such reactions is motivated by the intriguing and complicated kinetic phenomena that seem to be their hallmark. These phenomena include: multiple rate limiting steps - more than one of the elementary steps in the sequence can limit the rate depending on the conditions, steady-state multiplicity - the dependence of the rate on an operating variable is mulcivalued, typically in the form of a hysteresis (transitions between the different states occur at ignition and extinction points), periodic and aperiodic oscillations - the rate fluctuates in a repeatable (periodic) or non-repeatable (aperiodic) fashion, and spatially nonuniform siates - state gradients (of concentration, temperature) exist on the catalyst surface that may be timie-dependent (spatio-temporal phenomena).

The first three yeurs of our research (entitled 'Surface Analyses and Modelling of Rate Multiplicity and Instabilities') has followed two parallel paths which have a common destination and which together provide a framework for the proposed new research. (Our specific accomplishments of the first three years of DOE-BES sponsored research are summarized in section 2 of this report.)

The first path has involved the development of a combined experimental/modelling $\&$ analysis methor.ology for constructing feasible mechanistic sequences and their corresponding kinetic models of catalytic reactions that exhibit multiple rate behavior. The rather well-studied $\mathrm{Pt}$ catalyzed $\mathrm{CO}$ oxidation served as the test reaction. Our approach is comprised of an experimental part, which involves the measurement of basic kinetic features (apparent reactioni orders, activation energy) and multiplicity features (location of ignition and extinction points) over a wide range of conditions (catalyst temperature, total pressure, feed composition), and a kinetic mocelling part, in which potential reaction sequences are constructed and screened based on their ability to predict the experimentally observed kinetic and multiplicity features over a wide range of conditions. Singularity theory is used as a tool to did in the analysis of the latter and in the estimation of kinetic parameters based on a fit of the location of ignition and extincrion points.

The second path has involved the development of an under-utilized (in catalysis) spectroscopic technique, Fourier transform infrared emission spectroscopy' (FTIRES), to monitor the surface of a catalyst during reaction. FTIRES provides a means of monitoring the vibrational spectra corresponding to adsorba 
to substrate modes. We have demonstrated its utility for some simple systems (CO and NO on supported $\mathrm{Pt}$ ).

\section{Summary of Accomplishments}

The project has served as the basis for the Ph.D. dissertation work of two students, Martha Garske and David Sullivan. Their research projects has been concerned with topics (i) - (vi) listed below: M. Garske: topics (i) - (iii); D. Sullivan: topics (iv) and (v). The following will summarize accomplishments in the project to date.

\section{a. Kinetics and modeling studies of $\mathrm{CO}$ oxidation on $\mathbf{P t}$}

In this project there have been four main accomplishments:

(i) Construction of catalytic wire experiment designed for wide range of total pressures.

(ii) Experimental study of the kinetics and multiplicity features of $\mathrm{CO}$ oxidation on a $\mathrm{Pt}$ wire over a wide range of conditions.

(iii) Kinetic modelling of Pt-catalyzed CO oxidation: development of new models that predict basic kinetic and multiplicity trends of UHV data and that predict the correct qualitative features at higher pressure; development of a kinetic parameter estimation scheme which involves fitting a multivalued kinetic model to singular and nonsingular data.

(iv) Modelling of hot spot formation on a temperature-controlled catalytic wire: this study helps to elucidate the nonisothermal features of the $\mathrm{CO}$ oxidation data and the data of others.

This part of the research has resulted in two publications, one in preparation, and several presentations (see below).

\section{b. Development of Fourier transform infrared emission spectroscopy}

In this project there have been two main accomplishments:

(iv) Construction of an experiment involving the advancement of an unutilized tool for monitoring adsorbed species: Fourier transform infrared emission spectroscopy (FTIRES).

(v) Recent application of FTIRES to the monitoring of $\mathrm{CO}$ adsorption on $\mathrm{Pt} / \mathrm{Al}_{2} \mathrm{O}_{3}$ and of the $\mathrm{CO}-\mathrm{NO}$ reaction on $\mathrm{Pt} / \mathrm{Al}_{2} \mathrm{O}_{3}$. Experiment is now designed for steady-state kinetics and in situ FTIRES.

A manuscript is currently under preparation which deals with these developmental issues associated with FTIRES; these were presented at the 1990 AIChE Meeting (see below). 


\section{Summary of the presentations and publications from the research}

\section{Presentations}

Garske, M. E. and Harold, M. P. (speaker), Rate Multiplicity in Carbon Monoxide Oxidation on a Platinum Wire, presented in 'Reaction Engineering' session, North American Catalysis Society Meeting, Dearborn, MI (1989).

Harold, M. P. (speaker), and Garske, M. E., On the Causes of Rate Multiplicity in CO Oxidation on Platinum: The Impact of Total Pressure, presented in 'Pattern Formation in Chemical Reacting Systems' session, Annual AIChE Meeting, San Francisco, CA (1989).

Harold, M.P., Multiple Rate States in CO Oxidation on Platinum: Kinetic Model Development and Discrimination, seminar, Pennsylvania State University (1990).

Harold, M.P., Multiplicity of States in Catalytic Chemical Reactions: Applications of Nonlinear Analysis, seminar, Department of Mathematics, University of Massachusetts (1990).

Harold, M.P., Multiple Rate States in CO Oxidation on Platinum: Kinetic Model Development and Discrimination, seminar, Catalysis group at the du Pont Experimental Station (1990).

Garske, M. E., and Harold, M. P. (speaker), Distortion of Observed Multiplicity Features by Temperature Nonuniformitie's Along an Electrically Heated Pt Wire During CO Oxidation, presented in 'Chemical Reactor Stability and Dynamics' session, Annual AIChE Meeting, Chicago (November, 1990).

Sullivan, D. (speaker), Harold, M., and Conner, W. C., Surface Analysis with FTIR Emission Spectroscopy, presented in 'General Papers in Catalysis II,' session, Annual AIChE Meeting, Chicago (November, 1990).

\section{Manuscripts}

Harold, M. O., and Garske, M. E., Kinetics and Multiple Rate States of CO Oxidation on Platinum: Model Development and Multiplicity Analysis, to appear in J. Catal. (1991).

Harold, M. P., and Garske, M. E., Kinetics and Multiple Rate States of CO Oxidation on Platinum: Linking UHV and Atmospheric Pressure Kinetic Behavior, to appear in J. Catal. (1991).

Garske, M. E., and Harold, M. P., Kinetics and Multiple Rate States of CO Oxidation on a Platinum Wire: Isothermal and Nonisothermal Behaviors, in preparation and to be submitted to Chem. Eng. Sci.' (February, 1991). 

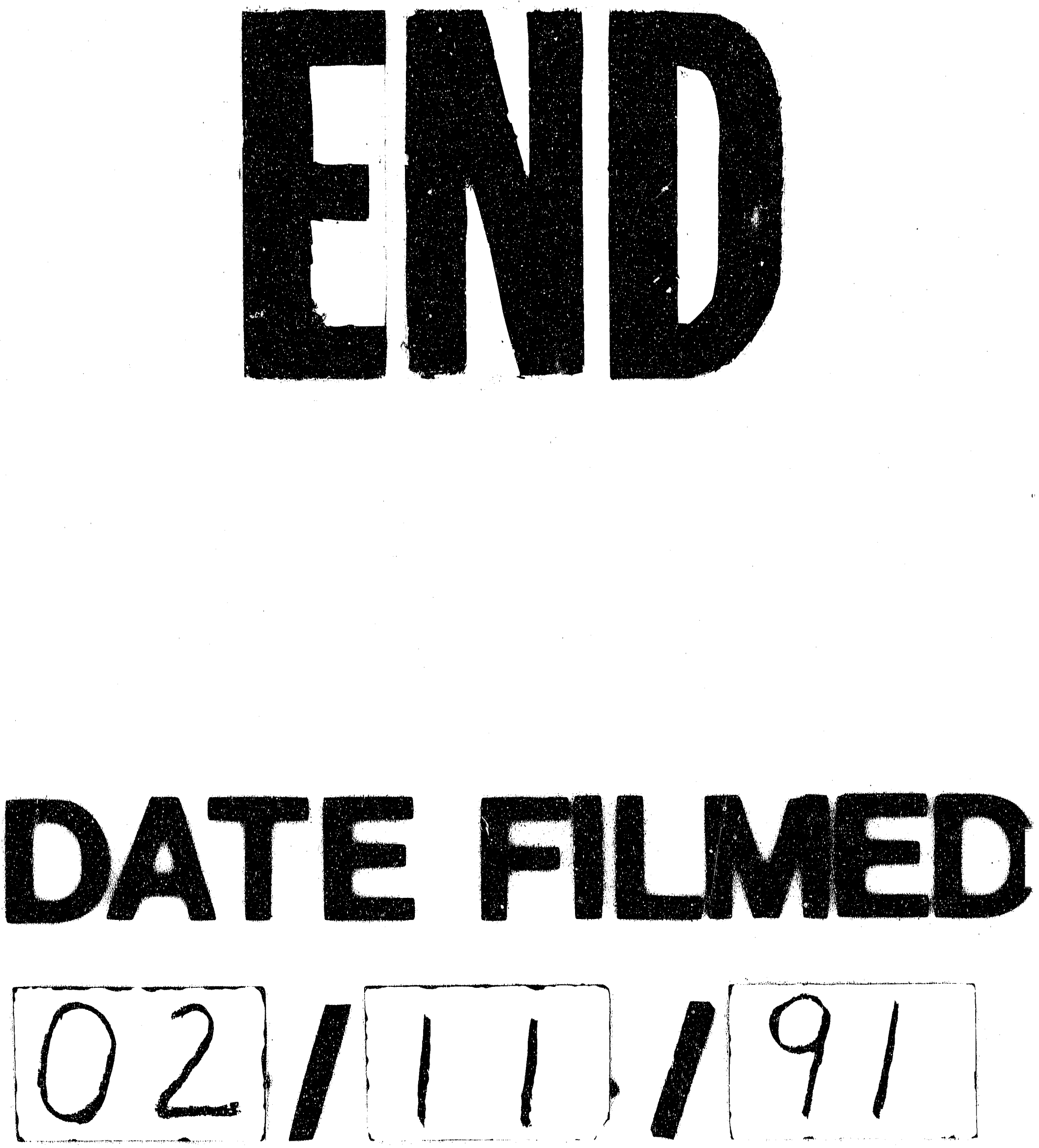
